\title{
Conocimientos y conductas preventivas sobre cáncer cérvico-uterino y virus papiloma humano en un grupo de adolescentes chilenas
}

\author{
M. Teresa Urrutia, Ximena Concha, Giselle Riquelme y Oslando Padilla
}

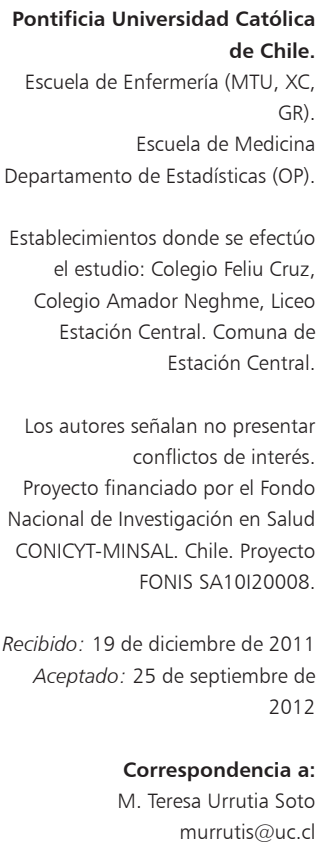

Pontificia Universidad Católica de Chile. Escuela de Enfermería (MTU, XC,

Escuela de Medicin Departamento de Estadísticas (OP)

Establecimientos donde se efectúo el estudio: Colegio Feliu Cruz, Colegio Amador Neghme, Liceo Estación Central. Comuna de Estación Central.

Los autores señalan no presentar conflictos de interés.

Proyecto financiado por el Fondo Nacional de Investigación en Salud CONICYT-MINSAL. Chile. Proyecto FONIS SA10120008.

Recibido: 19 de diciembre de 2011 Aceptado: 25 de septiembre de

Correspondencia a: M. Teresa Urrutia Soto murrutis@uc.cl

\section{$\mathrm{E}$} 1 virus papiloma humano (VPH) es una infección de transmisión sexual (ITS) frecuente entre mujeres y hombres, bastante común en población joven ${ }^{1}$, y reconocido como el factor de riesgo más importante para desarrollar cáncer cérvico-uterino (CC). Dada la presencia de una vacuna contra el VPH, junto a un tamizaje conocido, el CC es considerado uno de los cánceres más fácilmente prevenibles ${ }^{2}$.

En Chile están disponibles dos vacunas contra el VPH; sin embargo, por su costo no son accesibles a la población de bajos recursos económicos, generando una importante inequidad en el acceso a este recurso preventivo en el país. Cabe señalar que la vacuna no remplaza el tamizaje con la prueba de Papanicolaou ${ }^{3,4}$, y dado que no se encuentra disponible para toda la población, esfuerzos para incrementar las conductas preventivas tanto primarias (conductas sexuales) como secundarias (Papanicolaou), debieran seguir desarrollándose en nuestro país.

Por otro lado, las adolescentes, si bien no cumplen el criterio de edad para poder realizarse el tamizaje en Chile, se encuentran en riesgo de contraer el VPH, lo que sumado a la disparidad de información y falta de acceso a la vacuna en aquellos caso de bajos recursos, hacen de esta población un grupo más susceptible de desarrollar en el futuro un CC. Ferreccio y cols, en un estudio en Chile, demostraron una prevalencia de $14 \%$ de infección por VPH, dentro de la cual $71 \%$ era de alto riesgo. La edad de mayor prevalencia fue el rango entre 15 y 24 años ${ }^{5}$.

El objetivo del presente estudio es describir el grado de conocimiento que tiene un grupo de adolescentes chilenas acerca del CC y el VPH y su relación con las conductas preventivas.

\section{Población y Método}

Estudio analítico de corte transversal realizado en un grupo de 226 adolescentes de primero a cuarto medio de tres colegios municipalizados en una comuna del área norte de la Región Metropolitana en Santiago Chile, durante los meses de abril y mayo de 2011. El muestreo consideró la selección en primer lugar de los cursos que ingresarían de cada uno de los colegios y posteriormente el número de adolescentes por curso.

Las variables en estudio corresponden a variables demográficas, conocimientos acerca del CC y conductas preventivas. Los conocimientos fueron medidos con el cuestionario CEC-66 validado en población adolescente chilena $^{6}$, el que presenta un total de 66 ítems distribuidos en cinco dimensiones. El alpha de Cronbach en esta muestra fue de 0,90 . Las conductas preventivas consideran la 
presencia de control ginecológico (con matrona o médico ginecólogo), la realización del Papanicolaou, el uso de condón durante los contactos sexuales y la vacunación contra el VPH. El instrumento fue auto-aplicado, en una sala de cada colegio. El tiempo promedio en responder el cuestionario fue de $20 \mathrm{~min}$. El análisis de los datos se realizó mediante el programa estadístico SPSS 18.0. Se realizaron medidas de tendencia central y de dispersión, análisis de frecuencia y prueba de $\square^{2}$ para el análisis de variables categóricas. El estudio fue aprobado por el Comité de Ética de la Escuela de Enfermería de la Pontificia Universidad Católica de Chile. Se solicitó la firma de consentimiento informado al apoderado de la adolescente y una vez autorizada la participación por el apoderado se solicitó el consentimiento a la estudiante.

\section{Resultados}

El promedio de edad de las adolescentes fue de 16,18 $\pm 1,29$ años con un rango entre 13 y 19 años. Del total de adolescentes, dos de ellas estaban casadas, cuatro convivían y las restantes eran solteras. El 1,8\% de las encuestadas señaló tener un hijo. Respecto del sistema de salud, 13,5\% no tenía sistema de salud, 1,6\% seguro de salud en Fuerzas Armadas, 6,8\% ISAPRE (seguro privado) y $81,1 \%$ FONASA (Fondo Nacional de Salud). En relación al hábito tabáquico, 49,2\% consumía cigarrillos. El 12\% refirió haber tenido algún familiar con CC.

Grado de conocimiento de las adolescentes. En la dimensión 1 sobre definición y diagnóstico de CC, 75,8\% de la muestra reconoció que el CC compromete sólo una parte del útero y $85 \%$ estuvo muy de acuerdo o de acuerdo en que el diagnóstico de $\mathrm{CC}$ se realiza con biopsia. Cabe señalar que más de la mitad de las adolescentes afirmó que el CC se diagnostica mediante examen de sangre y cerca de $70 \%$ mediante examen de orina (Tabla 1 ).

Acerca de los factores asociados al CC (Tabla 2), el tener múltiples parejas sexuales fue reconocido por 70,8\% como factor de riesgo y la infección por VPH por 78,3\%. El factor hereditario fue señalado como factor de riesgo por $60,6 \%$ de la muestra en estudio. Como medidas pre- ventivas, el control ginecológico fue reconocido por $98,7 \%$ como medida para prevenir el CC; sin embargo, $60,1 \%$ de las adolescentes señaló que para poder vacunarse contra el VPH es necesario tener familiares con CC. El 23\% de las adolescentes reconoció al tabaco como factor de riesgo.

Más de $85 \%$ de la muestra señaló que el Papanicolaou detecta el CC en etapa pre invasora, incluyendo la presencia de VPH. El 65,8\% indicó que es requisito para tomarse el Papanicolaou estar sexualmente activa, $52,7 \%$ que es necesario tener más de una pareja sexual, 49,2\% que es necesario haber tenido una enfermedad de transmisión sexual y $50 \%$ que es necesario tener hijos. En relación a la frecuencia de toma del Papanicolaou, 31,4\% afirmó estar de acuerdo o muy en acuerdo con que debe ser cada tres años (Tabla 2).

El 47,8\% reconoció que el VPH se transmite por contacto sexual sin protección y $68,2 \%$ por relaciones sexuales sin protección (Tabla 3 ). Cabe señalar que sobre $68 \%$ de las adolescentes encuestadas consideró la infección por VPH como sintomática, ya fuese por presencia de sangrado o prurito.

El 23\% de la población desconocía la existencia de la vacuna contra el VPH (Tabla 3), 68,6\% señaló que es necesario haber tenido relaciones sexuales para recibir la vacuna y $42,7 \%$ que es necesario tener más de una pareja sexual.

Al analizar las conductas preventivas, 56,2\% de las adolescentes refirió que nunca había sido examinada por matrona o médico ginecólogo. Del grupo que había sido examinada, 64,6\% lo fue hacía menos de un año, 9,9\% hacía más de un año y $26,2 \%$ no recordaba la fecha. Al analizar el motivo por el cual acudieron a control ginecológico, 39,2\% fue en búsqueda de anticoncepción, 28,9\% por problemas menstruales, $13,4 \%$ por control anual y $18,6 \%$ por otra causa, entre las cuales se encontraba la consulta por posible embarazo.

Un total de 21 adolescentes (9,5\% de la población total) refería haber tenido un Papanicolaou, encontrándose sólo dos de ellas con un test mayor a tres años. Cabe señalar que de las 21 adolescentes que se habían tomado el examen, dos habían tenido contacto sexual sin penetración y 18

Tabla 1. Respuestas entregadas por las adolescentes en la dimensión 1 del instrumento: definición y diagnóstico del cáncer cérvico-uterino

\begin{tabular}{|c|c|c|c|c|c|c|c|c|c|c|c|}
\hline \multirow[b]{2}{*}{ El CC compromete... } & \multicolumn{2}{|c|}{ Muy de acuerdo } & \multicolumn{2}{|c|}{ De acuerdo } & \multicolumn{2}{|c|}{ En desacuerdo } & \multicolumn{2}{|c|}{ Muy en desacuerdo } & \multicolumn{2}{|c|}{ No contesta } & \multirow[t]{2}{*}{ Total } \\
\hline & $\mathrm{n}$ & $(\%)$ & $\mathrm{n}$ & (\%) & $\mathrm{n}$ & (\%) & $\mathrm{n}$ & $(\%)$ & $\mathrm{n}$ & $(\%)$ & \\
\hline Todos los órganos genitales de la mujer & 37 & $(16,4)$ & 108 & $(47,8)$ & 61 & (27) & 17 & $(7,5)$ & 3 & $(1,3)$ & 226 \\
\hline Parte del útero de la mujer & 80 & $(35,4)$ & 90 & $(39,8)$ & 45 & $(19,9)$ & 10 & $(4,4)$ & 1 & $(0,4)$ & 226 \\
\hline \multicolumn{12}{|l|}{ El CC se diagnostica mediante.. } \\
\hline Biopsia (muestra del tejido del cuello uterino para análisis) & 93 & $(41,2)$ & 99 & $(43,8)$ & 26 & $(11,5)$ & 6 & $(2,7)$ & 2 & $(0,9)$ & 226 \\
\hline Examen de sangre & 39 & $(17,3)$ & 90 & $(39,8)$ & 76 & $(33,6)$ & 16 & $(7,1)$ & 5 & $(2,2)$ & 226 \\
\hline Examen de orina & 42 & $(18,6)$ & 109 & $(48,2)$ & 59 & $(26,1)$ & 12 & $(5,3)$ & 4 & $(1,8)$ & 226 \\
\hline
\end{tabular}


Tabla 2. Respuestas entregadas por las adolescentes en la dimensión 2 y 3 del instrumento: factores asociado al cáncer cérvico-uterino y su prevención

Muy de acuerdo De acuerdo En desacuerdo Muy en desacuerdo No contesta Tota

Dentro de los factores relacionados al CC se encuentra:

Tener múltiples parejas sexuales

Tener relaciones sexuales antes de los 16 años

Tener familiares con cáncer cérvico-uterino

Tener mala alimentación

Tener infección por el virus papiloma humano

Haber tenido muchos embarazos

Usar anticonceptivos orales

Usar los baños públicos

Fumar cigarrillos

Tomar alcohol

Medidas preventivas. .

Ir a control ginecológico con médico o matrona previene el CC

Tener antecedentes familiares de CC es requisito para vacunarse

El Papanicolaou detecta...

El cáncer cérvico-uterino

El pre- cáncer cérvico-uterino

Para tomarse el Papanicolaou es necesario..

Tener relaciones sexuales (sexualmente activa)

Haber tenido relaciones sexuales (aunque sea una vez)

Haber tenido más de una pareja sexual

Haber tenido la primera relación sexual hace 3 años

Haber tenido una enfermedad de transmisión sexual

Tener alguna molestia en los genitales

Tener hijos

El Papanicolaou se debe tomar...

Anualmente (todos los años)

Cada 3 años

Las veces que se lo tome el Pap depende de la edad de la mujer

CC: cáncer cérvico-uterino

\begin{tabular}{|c|c|c|c|c|c|c|c|c|c|c|}
\hline$n$ & (\%) & $n$ & (\%) & $n$ & (\%) & $n$ & (\%) & $n$ & (\%) & \\
\hline 89 & $(39,4)$ & 71 & $(31,4)$ & 55 & $(24,3)$ & 9 & (4) & 2 & $(0,9)$ & 226 \\
\hline 23 & $(10,2)$ & 46 & $(20,4)$ & 116 & $(51,3)$ & 38 & $(18,8)$ & 3 & $(1,3)$ & 226 \\
\hline 50 & $(22,1)$ & 87 & $(38,5)$ & 65 & $(28,8)$ & 23 & $(10,2)$ & 1 & $(0,4)$ & 226 \\
\hline 2 & $(0,9)$ & 35 & $(15,5)$ & 121 & $(53,5)$ & 64 & $(28,3)$ & 4 & $(1,8)$ & 226 \\
\hline 60 & $(26,5)$ & 117 & $(51,8)$ & 32 & $(14,2)$ & 15 & $(6,6)$ & 2 & $(0,9)$ & 226 \\
\hline 31 & $(13,7)$ & 56 & $(24,8)$ & 100 & $(44,2)$ & 38 & $(16,8)$ & 1 & $(0,4)$ & 226 \\
\hline 4 & $(1,8)$ & 41 & $(18,1)$ & 122 & (54) & 56 & $(24,8)$ & 3 & $(1,3)$ & 226 \\
\hline 15 & $(6,6)$ & 83 & $(36,7)$ & 88 & $(38,9)$ & 37 & $(16,4)$ & 3 & $(1,3)$ & 226 \\
\hline 7 & $(3,1)$ & 45 & $(19,9)$ & 121 & $(53,5)$ & 48 & $(21,2)$ & 5 & $(2,2)$ & 226 \\
\hline 6 & $(2,7)$ & 35 & $(15,5)$ & 129 & $(57,1)$ & 53 & $(23,5)$ & 3 & $(1,3)$ & 226 \\
\hline 155 & $(68,6)$ & 68 & $(30,1)$ & 2 & $(0,9)$ & 1 & $(0,4)$ & 0 & $(-)$ & 226 \\
\hline 55 & $(24,3)$ & 81 & $(35,8)$ & 67 & $(29,6)$ & 18 & (8) & 5 & $(2,2)$ & 226 \\
\hline 108 & $(47,8)$ & 90 & $(39,8)$ & 21 & $(9,3)$ & 4 & $(1,8)$ & 3 & $(1,3)$ & 226 \\
\hline 85 & $(37,6)$ & 119 & $(52,7)$ & 17 & $(7,5)$ & 3 & $(1,3)$ & 2 & $(0,9)$ & 226 \\
\hline 65 & $(28,8)$ & 81 & $(35,8)$ & 60 & $(26,5)$ & 17 & $(7,5)$ & 3 & $(1,3)$ & 226 \\
\hline 66 & $(29,2)$ & 89 & $(39,4)$ & 51 & $(22,6)$ & 16 & $(7,1)$ & 4 & $(1,8)$ & 226 \\
\hline 46 & $(20,4)$ & 73 & $(32,3)$ & 75 & $(33,2)$ & 27 & $(11,9)$ & 5 & $(2,2)$ & 226 \\
\hline 18 & (8) & 48 & $(21,2)$ & 103 & $(45,6)$ & 52 & (23) & 5 & $(2,2)$ & 226 \\
\hline 46 & $(20,4)$ & 65 & $(28,8)$ & 71 & $(31,4)$ & 39 & $(17,3)$ & 5 & $(2,2)$ & 226 \\
\hline 65 & $(28,8)$ & 83 & $(36,7)$ & 50 & $(22,1)$ & 24 & $(10,6)$ & 4 & $(1,8)$ & 226 \\
\hline 48 & $(21,2)$ & 65 & $(28,8)$ & 70 & (31) & 37 & $(16,4)$ & 6 & $(2,7)$ & 226 \\
\hline 82 & $(36,3)$ & 76 & $(33,6)$ & 47 & $(20,8)$ & 15 & $(6,6)$ & 6 & $(2,7)$ & 226 \\
\hline 19 & $(8,4)$ & 52 & (23) & 113 & (50) & 38 & $(16,8)$ & 4 & $(1,8)$ & 226 \\
\hline 33 & $(14,6)$ & 74 & $(32,7)$ & 85 & $(37,6)$ & 29 & $(12,8)$ & 5 & $(2,2)$ & 226 \\
\hline
\end{tabular}

\section{Tabla 3. Respuestas entregadas por las adolescentes en la dimensión 4 y 5 del instrumento: virus papiloma / vacuna y cáncer cérvico-uterino}

\section{Muy de acuerdo}

El virus relacionado al cáncer cérvico-uterino se transmite por..

Contacto sexual (sin penetración) sin protección (condón)

Relaciones sexuales (con penetración) sin protección (condón)

n $\quad(\%)$

$39 \quad(17,3)$

De acuerdo

En desacuerdo Muy en desacuerdo

No contesta Total

Un síntoma de la infección relacionada al virus que produce el cáncer cérvico-uterino es (son)...

Flujo o líquido genital de mal olor

Picazón en los genitales

Verrugas (ampollas) genitales

Ardor al orinar

Sangrado genital diferente a la menstruación

Para vacunarse (es necesario)...

Haber tenido relaciones sexuales

Haber tenido más de una pareja sexual

Hay que tener más de 15 años de edad

Hay que tener el Papanicolaou

No hay vacunas contra el virus que se relaciona al cáncer

cérvico-uterino

$\begin{array}{llrlll}41 & (18,1) & 121 & (53,5) & 51 & (22,6) \\ 44 & (19,5) & 110 & (48,7) & 57 & (25,2) \\ 31 & (13,7) & 93 & (41,2) & 84 & (37,2) \\ 53 & (23,5) & 112 & (49,6) & 48 & (21,2) \\ 41 & (18,1) & 121 & (53,5) & 48 & (21,2)\end{array}$

$n$
27
15

$\begin{array}{cc}(\%) & n \\ (11,9) & 4 \\ (6,6) & 3\end{array}$

(\%)

$(1,8) \quad 226$

$(1,3) \quad 226$
$68 \quad(30,1)$

$(23,9)$

42

38

52

21

\section{$(24,8)$}

$$
(18,6)
$$

$$
(16,8)
$$

(23)

$(9,3)$

\begin{abstract}
99
31
\end{abstract}

$\begin{array}{lll}77 & (34,1) & 76 \\ 87 & (38,5) & 71\end{array}$

88 (38) 60

\section{$(20,4)$ \\ $(33,6)$ \\ $(31,4)$}

$(26,5)$

$(13,7) \quad 94$

$(41,6)$
$(21,2)$

11
11
16
12
12

$(4,9)$

$(4,9)$

$(7,1)$

$(5,3)$

$(5,3)$

19

$(8,4)$

$(11,1)$

$(9,3)$

$(8,8)$

$(31,9)$

$\begin{array}{lll}2 & (0,9) & 226 \\ 4 & (1,8) & 226 \\ 2 & (0,9) & 226 \\ 1 & (0,4) & 226 \\ 4 & (1,8) & 226\end{array}$


relaciones sexuales. Si se considera solamente al grupo que refirió haber tenido relaciones sexuales, el porcentaje de adolescentes que había tenido un Papanicolaou es de $17,5 \%$. De las adolescentes que se habían tomado el examen, $65 \%$ lo había hecho por control y $35 \%$ por sugerencia del profesional que las atendió al encontrar un examen físico sospechoso. El 6,2\% de las adolecentes refirió conocer alguna "vacuna contra el CC" y 100\% de la muestra refería no haber recibido la vacuna.

En relación a la actividad sexual, 45,7\% (n: 102) de las adolescentes refería no tener experiencia sexual (ni contacto genital ni relaciones sexuales), 8,1\% (n: 18) refirió sólo contacto genital (sin penetración) y 46,2\% (n: 103) había tenido relaciones sexuales con coito.

Del grupo de adolescentes con actividad sexual, 50\% de la población tuvo su primer contacto sexual ( $\sin$ penetración) antes de los 14 años y 50\% tuvo su primera relación sexual con penetración antes de los 15 años. Al analizar el número de parejas sexuales el promedio era de $1,78 \pm 1,50$ con un rango de 1 a 10 personas en el caso del contacto genital sin penetración y un promedio de1,61 $\pm 1,25$ con un rango de 1 a 7 para las relaciones sexuales con penetración. Al analizar el uso del condón, $24,8 \%$ refirió usarlo siempre o casi siempre al momento de tener contacto genital y $31,1 \%$ al momento de tener relaciones sexuales con penetración.

El 71,3\% del grupo de adolescentes con actividad sexual señaló estar utilizando algún método de planificación familiar, siendo en $35 \%$ anticoncepción oral, $7 \%$ implante, $5 \%$ condón, $5 \%$ coito interrumpido, 3\% método calendario, 3\% dispositivo intrauterino y $42 \%$ refería una combinación entre diferentes métodos. En relación a infecciones de transmisión sexual, solamente dos adolescentes refirieron haber tenido algún tipo, no recordando el nombre de la infección.

Para el análisis de la relación entre las conductas preventivas y el conocimiento de las adolescentes se compararon las respuestas correctas del grupo con la conducta preventiva presente versus el grupo con la conducta preventiva ausente. Los resultados señalan asociaciones significativas sólo con algunos tópicos del cuestionario de conocimientos, lo que señala que las conductas preventivas que las adolescentes llevan a cabo están poco relacionadas con el conocimiento que tienen respecto del CC y sus formas de prevención (Tabla 4).

\section{Discusión}

El presente estudio es el primero en medir el conocimiento de adolescentes chilenas acerca de CC y VPH, lo que podría servir como un diagnóstico inicial en este grupo en particular, en relación al tema de interés. La principal debilidad radica en que, si bien es una muestra representativa según colegio y curso, está formada sólo por aquellas adolescentes que obtuvieron el consentimiento de sus padres, que accedieron a participar y de colegios municipalizados de una comuna específica, lo que hace que sea un estudio no representativo de las adolescentes en general.

Cabe destacar que el factor herencia identificado por las adolescentes de este estudio como factor de riesgo también ha sido reportado previamente como un concepto errado en las mujeres por otros autores ${ }^{7-9}$. En un estudio realizado en población chilena ${ }^{10}, 50 \%$ de las mujeres señaló que la herencia es una causa del CC, situación que es errónea, dado que esta neoplasia es uno de los cánceres no asociado al factor genético, sino más bien a las conductas sexuales de las personas. Cabe señalar que el estudio chileno ${ }^{10}$ fue realizado en población de mujeres mayores de 18 años de edad, adscritas a un centro secundario de atención del sistema público, característica que siendo diferente a la muestra del presente estudio, no logra modificar la percepción errónea respecto de este factor de riesgo.

En relación a las conductas preventivas de las adolescentes, llama la atención que más de $50 \%$ de la población no hubiera sido examinada por ginecólogo o por matrona. Esto es importante de destacar, si consideramos que 100\% de la muestra tenía 13 años o más, edad que según la recomendación internacional ${ }^{11}$ se encuentra en el rango etario para tener a lo menos un control con fines diagnósticos o simplemente con fines educativos. Si bien se debe reconocer que la norma internacional puede no ser llevada a cabo por la totalidad de la población, es importante estimular en las adolescentes medidas de auto-cuidado entre las cuales se encuentra asistir a un control ginecológico a edad temprana, independiente de si tienen o no actividad sexual. En el grupo de estudio, sólo 43,8\% refirió haber acudido a control ginecológico con matrona o médico.

La infección por VPH afecta a un alto porcentaje de las mujeres jóvenes de todo el mundo, principalmente adolescentes ${ }^{12}$ y de países en desarrollo ${ }^{13-16}$. La alta incidencia de infección por VPH está asociada al inicio precoz de la actividad sexual, mayor frecuencia de actividad sexual en la etapa de adolescentes y adultos jóvenes y mayor

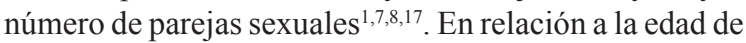
inicio de actividad sexual en este estudio, los resultados coinciden con los reportados por investigaciones previas en nuestro país ${ }^{18,19}$. Sin embargo, es destacable que no todo el grupo de adolescentes que es sexualmente activa utiliza algún método de planificación familiar, y por otro lado, que sólo un porcentaje cercano a $30 \%$ de la muestra sexualmente activa refiere usar condón en todas las relaciones sexuales, situación que las pone en alto riesgo de contraer una infección de transmisión sexual, entre ellas la infección por VPH. Lo anterior se une al porcentaje bajo de enfermedad de transmisión sexual reportada, la que podría, por ende, estar sub-diagnosticada.

Cabe señalar que la importancia de la infección por VPH radica en que siendo el principal factor etiológico 
Tabla 4. Conductas preventivas de las adolescentes y su relación con el grado de conocimiento

Conducta adolescente

Haber tenido un control ginecológico

Haber tenido un Papanicolaou

Uso de condón en contactos sexuales

Uso de condón en relaciones sexuales

\section{Ubicación del cáncer}

\section{Forma de detección del CC}

Tener múltiples parejas sexuales como factor de riesgo

Tener relaciones sexuales antes de los 16 años como factor de riesgo

Tener infección por el VPH como factor de riesgo

Transmisión del virus por contacto genital (sin penetración)

La transmisión del virus por relaciones sexuales sin condón

Importancia de atrasar el inicio de las relaciones sexuales como forma de prevenir el CC

Importancia de limitar el número de parejas como forma de prevenir el CC

Importancia de usar condón en las relaciones sexuales como forma de prevenir el CC

Importancia de tomarse el Papanicolaou como forma de prevenir el CC

Importancia de vacunarse contra VPH como forma de prevenir el CC

Importancia de ir a control ginecológico como forma de prevenir el CC

La infección VPH no causa síntomas

La utilidad del Pap como forma de detectar el pre CC (lesión pre-invasora)

La utilidad del Pap como forma de detectar la infección del virus relacionado al CC
Valor $p$

$\mathrm{p}=\mathrm{NS}$

$\mathrm{p}=\mathrm{NS}$

$p=N S$

$\mathrm{p}=\mathrm{NS}$

$p=N S$

$\mathrm{p}=\mathrm{NS}$

$p=0,01$ *

$\mathrm{p}=\mathrm{NS}$

$p=N S$

$p=N S$

$\mathrm{p}=\mathrm{NS}$

$\mathrm{p}=\mathrm{NS}$

$p=0,04$ *

$\mathrm{p}=\mathrm{NS}$

$p<0,01$ *

$p<0,01$ *

$\mathrm{p}=\mathrm{NS}$

$p=N S$

$p=0,03$ *

$p=N S$

$p=N S$

$p=N S$

$p=N S$

$p=N S$

$p=N S$

$p=N S$

$p=N S$

$p=N S$

$p=N S$

$p=N S$

$p=N S$

$p=N S$

$\mathrm{p}=\mathrm{NS}$

$p=0,02$ *

$\mathrm{P}=\mathrm{NS}$

$p=0,02^{*}$

$\mathrm{p}=\mathrm{NS}$

$p=N S$

$p=N S$

$\mathrm{p}=\mathrm{NS}$

$p=N S$

$p=N S$

$p=N S$

$p=N S$

$p=N S$

$p=N S$

$p=N S$

$\mathrm{p}=\mathrm{NS}$

$p=N S$

$p=N S$

$\mathrm{p}=\mathrm{NS}$

$p=0,02$ *

$\mathrm{p}=\mathrm{NS}$

$p=N S$

$p=N S$

$\mathrm{p}=\mathrm{NS}$

$p=0,01$ *

$p=N S$

$\mathrm{p}=\mathrm{NS}$
$\mathrm{p}=\mathrm{NS}$

$p=N S$

$\mathrm{p}=\mathrm{NS}$

$p=N S$

$p=N S$

$\mathrm{p}=\mathrm{NS}$

* Valor $p<0,05$. CC: cáncer cérvico-uterino. 
del CC, sumado al desconocimiento de esta asociación por un segmento importante de la población y en particular de la población de riesgo, la transforma en un problema de salud pública para los países en desarrollo y en particular para aquellos países con alta incidencia de $\mathrm{CC}^{15}$. Respecto de la infección por el VPH, como agente etiológico, Gerend reportó durante el año 2007 que 56\% de la muestra estudiada en su investigación declaró no estar en riesgo de infección por el VPH a pesar que 78\% mantenía relaciones sexuales ${ }^{20}$.

Es necesario señalar la importancia de la educación a la población adolescente respecto del VPH y su relación con el CC. Estudios han demostrado que la entrega de información relativa al virus, además de incrementar el conocimiento propiamente tal ${ }^{21}$, incrementa la percepción de riesgo de desarrollar $\mathrm{CC}^{22,23}$. La falta de conocimiento determina la necesidad de instaurar programas educativos en edades tempranas que permitan a la población joven optar por comportamientos sexuales seguros una vez que inicien su vida sexual, situación que no está presente en esta muestra de estudio. Si bien los resultados de esta investigación señalan que las adolescentes reconocen la vacuna contra el VPH como una forma de prevenir el $\mathrm{CC}$, los resultados reflejan desinformación en cuanto a los requisitos para recibirla.

En Chile están disponibles dos vacunas contra el VPH, ambas consideradas seguras, bien toleradas e inmunogénicas $^{24}$. La recomendación de vacunación emitida por el Comité Consultivo de Inmunizaciones de la Sociedad Chilena de Infectología considera, entre otras recomendaciones, incluir a las mujeres que no han iniciado actividad sexual, de manera independiente de su edad (idealmente entre los 12 y 13 años), acompañada la indicación con educación correspondiente a sexualidad responsable, prevención de otras ITS, eficacia de la vacuna y necesidad que las vacunadas permanezcan adheridas al sistema de tamizaje. Dicho Comité en su Declaración recomienda también que las autoridades sanitarias consideren la incorporación de la vacunación universal contra VPH en el Programa Nacional de Inmunizaciones ${ }^{24}$.

Si bien el Programa Nacional de Cáncer Cérvicouterino en Chile tiene como grupo objetivo a las mujeres entre 25 y 64 años de edad, considerando la realización del tamizaje en este grupo etario, las recomendaciones emitidas en la Guía Clínica Cáncer Cérvico-uterino consideran relevante también "la educación a la población en relación a la importancia de esta patología, sus factores de riesgo y prevención, como también la vacunación por virus papiloma humano"25. Dado que la infección por VPH, mayoritariamente de los tipos VPH 16 y 18, constituye un problema de salud pública en nuestro país ${ }^{24}$, intervenciones educativas en población adolescente (principal grupo de riesgo de la infección) cobran importancia para cumplir dicha recomendación.
Según datos de la OMS, el CC es uno de los mayores problemas de salud pública en el mundo, constituyendo la primera causa de muerte en las mujeres de los países en desarrollo, como América Latina y el Caribe, donde la mortalidad por esta patología sólo es superada por países de África Oriental y Melanesia ${ }^{2}$. En nuestro país el programa de $\mathrm{CC}$ ha sido exitoso en disminuir la mortalidad ${ }^{26}$; se hace necesario, no obstante, invertir también esfuerzos para educar a la población de riesgo incrementando el grado de conocimiento sobre $\mathrm{CC}$, en especial acerca del agente más fuertemente relacionado que es el VPH, la importancia de prevenir la infección y las medidas para poder llevar a cabo dicha prevención.

En este nuevo paradigma, dada la presencia del VPH, la prevención secundaria, altamente desarrollada en Chile, deberá convivir con mejores y/o nuevas estrategias de prevención primaria ${ }^{27}$, enfocadas específicamente a la educación para evitar el contagio y a la vacunación cuando corresponda y cuando los medios económicos lo permitan, generando de esta forma una sinergia entre ambas intervenciones ${ }^{28}$. La necesidad de educación en este tema ha sido descrita como relevante ${ }^{29}$, dado que un gran porcentaje tanto de Chile ${ }^{10}$ como del mundo ${ }^{30-36}$ desconoce aspectos claves al respecto, lo que sumado al inicio de la actividad sexual, cada vez más precoz en los adolescentes, obliga a entregar información respecto de las vías de contagio y el riesgo real de contraer el $\mathrm{VPH}^{37}$.

\section{Resumen}

Introducción: El virus papiloma humano (VPH) es una infección de transmisión sexual frecuente en población joven, y reconocido como el factor de riesgo más importante para desarrollar cáncer cérvico-uterino (CC). Objetivo: Describir el grado de conocimiento que tiene un grupo de adolescentes chilenas en relación al $\mathrm{CC}$, al VPH y su relación con las conductas preventivas. Métodos: Estudio analítico, con una muestra aleatoria de 226 adolescentes de tres colegios municipalizados de la Región Metropolitana. Resultados: El 20\% de la muestra desconoce la presencia de una vacuna contra el VPH. Las adolescentes señalan como factor de riesgo para desarrollar CC tener múltiples parejas sexuales (70,8\%), VPH $(78,3 \%)$ y la herencia $(60,3 \%)$. La transmisión del VPH mediante relaciones sexuales sin protección es reconocida por $68,2 \%$ de la muestra. El $31,1 \%$ de las adolescentes sexualmente activas usa condón durante las relaciones sexuales. Aquellas adolescentes que usan condón señalan un conocimiento significativamente mejor solamente en lo que respecta al número de parejas sexuales y edad de inicio de las relaciones sexuales como factor de riesgo de CC. Conclusión: Las adolescentes conocen sobre la transmisión del VPH; sin embargo, las conductas preventivas no se relacionan con dicho conocimiento. 


\section{Referencias bibliográficas}

1.- Gerend M A, Barley J. Human papillomavirus vaccine acceptability among young adult men. Sex Transm Dis 2009; 36 (1): 58-62.

2.- Centers for Disease Control and Prevention [Internet]: Cervical cancer. [citado 2011 Nov 18]. Disponible en: http://www.cdc.gov/cancer/ cervical

3.- Organización Panamericana de la Salud. [Internet]: Expertos en la Américas piden mejoras para evitar muertes por cáncer de cuello uterino. [citado 2008 Sep 1]. Disponible en: http://www.paho.org/Spanish/DD/PIN/ ps080514.htm

4.- Pan American Health Organization and World Health Organization [Internet]: Regional strategy and plan of action for cervical cancer prevention and control. [citado 2008 Sep 1]. Disponible en: http://www.paho.org/English/ GOV/CE/ce140-14-e.pdf.

5.- Ferreccio C, Prado R, Luzoro A, Ampuero S, Snijders P, Meijer C, et al. Population-based prevalence and age distribution of human papillomavirus among women in Santiago, Chile. Cancer Epidemiol Biomarkers Prev 2004; 13 (12): 2271-6.

6.- Informe final proyecto FONIS SA 10 I20008. Prevención de cáncer cérvicouterino: Disminuyendo la disparidad en salud en adolescentes de colegios municipalizados y sus madres FONIS-COMINYT-MINSAL.

7.- McFarland D M. Cervical cancer and Pap smear screening in Botswana: Knowledge and perceptions. Int Nurs Rev 2003; 50 (3): 167-75.

8.- Lee M C. Knowledge, barriers, and motivators related to cervical cancer screening among Korean-American women. A focus group approach. Cancer Nurs 2000; 23 (3): 168-75.

9.- Lee P, Kwan T, Tam K, Chan K, Young P, Lo $\mathrm{S}$, et al. Beliefs about cervical cancer and human papillomavirus (HPV) and acceptability of HPV vaccination among Chinese women in Hong Kong. Prev Med 2007; 45 (2-3): 130-4.

10.- Urrutia M T. Creencias sobre Papanicolaou y cáncer cérvicouterino en un grupo de mujeres chilenas. Rev Chil Obstet Ginecol 2012; 77 (1): 3-10.

11.- American College of Obstetricians and Gynecologists [Internet]: Your first gynecologic visit. [citado 2011 Nov 11]. Disponible en: http://www.acog.org/ /media/For\%20Patients/ faq150.ashx

12.- The American College of Obstetricians and Gynecologists. Cervical Cancer in Adolescents: Screening, evaluation, and management. Obstet Ginecol 2010; 116 (2): 469-72.

13.- Sánchez M, Uribe F, Conde C. La infección por el virus del papiloma humano, un posible marcador biológico de comportamiento sexual en estudiantes universitarios. Salud Pública de Mex [Internet]. 2002 Jun [citado 2011 Ene 4];
44(5): 442-47. Disponible en http://www.scielo. org.mx/pdf/spm/v44n5/14034.pdf.

14.- Serman F. Cáncer cervicouterino: epidemiología, historia natural y rol del virus papiloma humano. Perspectivas en prevención y tratamiento. Rev Chil Obstet Ginocol 2002; 67 (4): 318-23.

15.- Kahn J, Ding L, Huang B, Zimet G, Rosenthal S, Frazier L. Intenciones de las madres respecto a que sus hijas y ellas mismas reciban la vacuna contra el virus del papiloma humano: estudio nacional de enfermeras. Pediatr 2009; 67(6): 325-31.

16.- National Cancer Institute [Internet]. HPV vaccines for cervical cancer. [citado $2011 \mathrm{Nov}$ 16]. Disponible en http://www.cancer.gov/ cancertopics/hpv-vaccines

17.- Jirojwong S, Manderson L. Beliefs and behaviors about Pap and breast self-examination among Thai immigrant women in Brisbane, Australia. Womens Health 2001; 33 (3-4): 47-66.

18.- González E, Molina T, Montero A, Martínez V, Leyton C. Comportamientos sexuales y diferencias de género en adolescentes usuarios de un sistema público de salud universitario. Rev Med Chile 2007; 135: 126-69.

19.- González M I, Aguirre M L, Tapia J. Caracterización de asistentes a consejería en sexualidad en un centro de salud integral de adolescentes. Rev Chil Pediatr 2005; 76 (6): 573-9.

20.- Gerend M, Magloire Z. Awareness, knowledge, and beliefs about human papillomavirus in a racially diverse sample of young adults. $\mathbf{J}$ Adolesc Health [Internet]. 2008 Mar [citado 2011 Ene 14]; 42 (3): 237-42. Disponible en: http://www.ncbi.nlm.nih.gov/pubmed/18295131

21.- Bazargan M, Bazargan S H, Farooq M, Baker R S. Correlates of cervical cancer screening among underserved Hispanic and African-American women. Prev Med 2004; 39: 465- 73.

22.- Owusu G A, Brown S B, Cready C M, Koella K, Trevino F, Urrutia-Rojas X, et al. Race and ethnic disparities in cervical cancer screening in a safety-net system. Matern Child Health J 2005; 9(3): 285-95.

23.- Aguilar J A, Leyva A G, Angulo D, Salinas A, Lazcano E C. Cervical cancer screening: Knowledge of Pap smear benefits and utilization in Mexico. Rev de Saude Publica 2003; 37 (1): 100-06.

24.- Abarca K, Valenzuela M T, Vergara R, Luchsinger V, Muñoz A, Jiménez de la Jara J, et al. Declaración del Comité Consultivo de Inmunizaciones de la Sociedad Chilena de Infectología respecto a la vacuna anti-virus papiloma humano. Septiembre 2008. Rev Chilena Infectol 2008; 25 (6): 428-34

25.- Ministerio de Salud. Gobierno de Chile. Guía
Clínica Cáncer Cérvicouterino. 2010. [citado 2012 Agosto 27]. Disponible en http://www. redsalud.gov.cl/portal/url/item/720bfefe91e9d2e de04001011f010ff2.pdf.

26.- Donoso E, Cuello M, Villarroel L. Reducción de la mortalidad por cáncer cérvico uterino en Chile, 1990-2003. Rev Chil Obstet y Ginecol 2006; 71 (5): 307-312.

27.- Howlett R, Miller A, Pasut G, Mai V. Defining a strategy to evaluate cervical cancer prevention and early detection in the era of HPV vaccination. Prev Med 2009; 48: 432-7.

28.- Kyrgiou M, Valasoulis G, Founta C, Koliopoulos G, Karakitsos P, Nasioutziki M. Clinical management of HPV-related disease of the lower genital tract. Ann NY Acad Sci 2010; 1205: 57-68.

29.- Wong P. HPV information needs, educational messages and chanel of delivery preferences: views from developing country with multiethnic populations. Vaccine 2009; 27: 1410-15.

30.- Marlow L, Waller J, Wardle J. The impact of HPV information on perceived risk of cervical cancer. Cancer Epidemiol Biomarkers Prev 2009; 18 (2): 373-6.

31.- Pitts M, Smith A, Croy S, Lyons A, Ryall $\mathrm{R}$, Garland S, et al. Singaporean men's knowledge of cervical cancer and human papillomavirus(HPV) and their attitudes towards HPV vaccination. Vaccine 2009; 27: 2989-93

32.- Pitts M, Dyson S, Doreen R, Garland S. Knowledge and awareness of human papillomavirus (HPV): attitudes towards HPV vaccination among a representative sample of women in Victoria, Australia. Sex Health 2009; 4 (3): 177-80.

33.- Do H, Seng P, Talbot T, Acorda E, Coronado G, Taylor V. HPV vaccine knowledge and beliefs among Cambodian American parents and community leaders. Asian Pac J Cancer Prev 2009; 10: 339-44.

34.- Hanisch R, Gustat J, Hagensee M E, Baena A, Salazar J E, Castro M V, et al. Knowledge of Pap screening and human papillomavirus among women attending clinics in Medellin, Colombia. Int J Gynecol Cancer 2008; 18: 1020-6.

35.- D'Urso J, Thompson-Robinson M, Chandler S. HPV knowledge and behaviors of black college students at a historically black university. J Am Coll Health 2007; 56(2): 159-63.

36.- Moreira E D, Oliveira B J, Ferraz F M, Costa S, Costa Filho J O, Karic G. Knowledge and attitudes about human papillomavirus, Pap smears, and cervical cancer among young women in Brazil: implications for health education and prevention. Int $\mathrm{J}$ Gynecol Cancer 2006; 16: 599-603.

37.- Kanato M, Saranrittichai K. Early experience of sexual intercourse- A risk factor for cervical cancer requiring specific intervention for teenagers. Asian Pac J Cancer Prev 2006; 7: $15-53$. 